\title{
A FORMAÇÃO PARA O TRABALHO: O PAPEL DOS INSTITUTOS FEDERAIS NA PRODUÇÃO DOS NOVOS INTELECTUAIS
}

\author{
K. R. MOTA ${ }^{1,}{ }^{*}$, C. H. S. ARAÚJO ${ }^{1}$, B. G. SANTOS ${ }^{1}$ \\ Instituto Federal de Educação, Ciência e Tecnologia de Goiás - Campus Anápolis \\ karla_mota@msn.com ${ }^{*}$
}

Submetido 20/03/2018 - Aceito 05/04/2018

DOI: $10.15628 /$ holos.2018.7120

\section{RESUMO}

O presente artigo tem por objetivo refletir sobre a possibilidade da formação para o trabalho atuar como instrumento de libertação dos trabalhadores. À luz da contribuição teórica oferecida por Marx, Engels, Gramsci e Lukács compreende-se que o trabalho é o elemento determinante na diferenciação do homem frente aos demais animais e na (re)construção da específica e particular natureza humana, convertendo o ser natural em ser social. As transformações sociais ocorridas sob o modo de produção capitalista distorcem o real sentido do trabalho, tornando a atividade executada pelo homem instrumento de alienação e aprisionamento. Ao se eleger o trabalho, na sua dimensão históricoontológica, como princípio educativo, tem-se a
\end{abstract}

possibilidade de permitir à classe trabalhadora produzir os seus próprios intelectuais e, portando, sua própria ideologia. Inicialmente, este estudo apresenta as dimensões históricas e ontológicas do trabalho, em seguida, discute a formação dos intelectuais orgânicos por meio da escola unitária gramsciana, por fim, reflete sobre a existência do gérmen desta perspectiva formativa dentro dos Institutos Federais de Educação, Ciência e Tecnologia, concluindo que estas intituições podem se configurar como um modelo contrahegemônico de educação profissional capaz de apontar o horizonte do "reino da liberdade" para a classe trabalhadora.

PALAVRAS-CHAVE: Educação Profissional, Trabalho como Princípio Educativo, Intelectual Orgânico

\section{THE FORMATION TO WORK: THE FEDERAL INSTITUTE ROLES IN THE PRODUCTIONS ABOUT THE "NEWS" INTELECTUALS}

\begin{abstract}
The present article aims about the possibility of the formation to work acts directly in the libertation of the workers. According to Marx, Engels, Gramsci e Lukács it is understandable that if the work is a major factor that makes the men differentiation among the others animals and in the human nature construction and reconstruction, converting the human being from being natural to being social. The capitalist way of life makes the real sense of work been distort, becoming it something that causes imprisonment and alienation. When choosing your work as an educational principle,
\end{abstract}

you have the possibility to produce your own intelectual, therefore, your own ideology. Initially, this study presentes the historic and ontological dimensions about of the work, and then discusses the unitary school gramsciana, finally, it meditate on the existence of the formative perspective germ in the Federal Institutes of Education, Science and Technology, concluding that these institutions can be figure as a counter-hegemonic model in the professional education able to show the "kingdom of freedom" to the working class.

KEYWORDS: Education, Work as Educational Principle, Organic Intellectual. 


\section{INTRODUÇÃO}

“Por esse pão pra comer, por esse chão pra dormir

A certidão pra nascer e a concessão pra sorrir

Por me deixar respirar, por me deixar existir"

(Chico Buarque,1971).

Uma breve reflexão sobre o trabalho, em um primeiro momento, pode fazer emergir sentimentos negativos, permitindo sua associação, quase que instintiva, aos vocábulos emprego, sofrimento, esforço, desgaste, salário, exploração, lucro, etc., refletindo as relações estiolantes construídas entre o capital e produção da existência humana, as quais inculcam no homem a falsa compreensão de que este formato de trabalho, tal como lhe é imposto, é algo natural e a única via para garantir o "pão pra comer" e o "chão pra dormir". Trata-se de concepções extremamente distanciadas e distorcidas de seu real significado ontológico, as quais se configuram, segundo Frigotto (2009), como um reflexo da mudança de sentido atribuída ao termo trabalho ao longo das transformações socioeconômicas ocorridas na humanidade, intensificadas principalmente pela ascensão do modo de produção capitalista.

Destarte, antes de iniciar considerações a favor do trabalho enquanto um princípio educativo torna-se necessário afirmar que a compreensão assumida para o vocábulo trabalho neste escrito aponta para um sentido diametralmente oposto dos supracitados e sublinhar que partimos da dimensão ontológica do trabalho, concebido enquanto uma "[...] categoria intermediária que possibilita o salto ontológico das formas pré-humanas para o ser social" (Antunes, 2007, p. 136, grifo nosso).

A formação para o trabalho, nesta perspectiva, deve fornecer as bases científicas e tecnológicas que fundamentam a atividade a ser desempenhada e, principalmente, desvelar as relações de força existentes no mundo do trabalho regido pelo modo de produção capitalista.

Compreendendo que os Institutos Federais de Educação, Ciência e Tecnologia fornecem uma formação técnica gratuita alicerçada sob as bases da escola unitária gramsciana, este artigo tem por objetivo discorrer sobre a possibilidade destas instituições apontarem o caminho para os trabalhadores - e futuros trabalhadores - encontrarem o "reino da liberdade" (Lukács, 1978).

Para tanto, estruturamos esta produção, fruto de um trabalho tanto muscular-nervoso quanto intelectual, em três momentos: o primeiro, fundamentado em Marx, Engels e Lukács, que pretende apresentar ao leitor qual a concepção do trabalho pode se configurar como um princípio educativo; o segundo, à luz de Gramsci, discorre sobre a possibilidade da classe trabalhadora formar seus próprios intelectuais orgânicos por meio da educação integrada; e, por fim, o terceiro momento compreende reflexões acerca dos supracitados institutos, os quais podem se configurar como instrumentos de travessia para uma "nova" realidade, pautada na atividade autodeterminada que assegure tempo livre para os trabalhadores fruírem da vida. 


\section{O TRABALHO COMO PRINCÍPIO EDUCATIVO: MAS DE QUAL TRABALHO ESTAMOS FALANDO?}

Para compreender as proposições acerca do trabalho como princípio educativo, deve-se partir da premissa de que o animal torna-se homem por meio do trabalho (Lukács, 1978). Diante de uma perspectiva histórica, o homem constitui-se de um ser que, diferentemente dos outros animais, não tem sua existência garantida pela natureza, necessitando intervir intencionalmente sobre o meio para responder às suas necessidades e se (re)produzir. Uma concepção presente na ontologia lukacsiana, a qual concebe "[...] o homem que trabalha, ou seja, o animal tornado homem através do trabalho, como um homem que dá respostas" (idem, ibidem, p. 5).

De acordo com Engels (2006, p. 2), a transformação do macaco, forma pré-humana, em homem foi viabilizada, primeiramente, por sua capacidade de ter os membros superiores livres, permitindo o "[...] desenvolvimento da mão sobre o resto do organismo". Este processo impulsionou, além de alterações fisiológicas em seu corpo, uma intervenção mais incisiva sobre o meio natural e, por consequência, sobre meio social, transformando qualitativamente as relações entre os seres "pré-humanos". Nesta configuração, o trabalho propiciou ações conjuntas e situações de ajuda mútua, evidenciando a vantagem das atividades coletivas para cada indivíduo e favorecendo o agrupamento dos membros em sociedade.

Este entendimento também é compartilhado por Lukács (1978), o qual afirma que a passagem do estágio da espécie animal com particular grau de desenvolvimento para o patamar de "gênero humano", de humanidade, só foi possível mediante o trabalho. Ou seja, por meio de sua vontade intencional de agir sobre a natureza o homem deixou de ser um ser puramente natural para torna-se um ser social, garantindo a forma, interna e externa, que lhe é característica.

Todavia, a emergência do capital, impeliu profundas alterações nas relações sociais. 0 homem deixou de autorrealizar-se na natureza por meio da produção de sua própria existência e satisfação das suas necessidades, para produzir a sua existência, a dos demais indivíduos e a mais-valia ${ }^{1}$ ao detentor dos meios de produção (Antunes, 2007). Este processo intensificou a divisão da esfera de atividades executadas pelos trabalhadores, culminando na distorção da forma como os indivíduos enxergam o trabalho. O modo de produção capitalista, portanto, introduziu um abismo separando o trabalho voltado para o genuíno atendimento das necessidades humanas, do trabalho que visa produzir, tão somente, mais capital e lucro.

De acordo com Marx \& Engels (1998), a imposição da divisão do trabalho não permite que o sujeito compreenda que a sua relação de cooperação com os outros homens na produção da existência humana se constitui de um poder social e uma força produtiva. Ao contrário, ao se impor uma esfera de atividade ao homem, esta se apresenta como:

\footnotetext{
[...] força estranha, situada fora deles, que não sabem de onde ela vem nem para onde vai, que, portanto, não podem mais dominar e que, inversamente, percorre agora uma série particular de fases e estágios de desenvolvimento, tão independente da vontade e da marcha da humanidade [...] (idem, ibidem, p. 30).
}

\footnotetext{
${ }^{1}$ A mais-valia é a forma específica de exploração do trabalhador assumida pelo modo de produção capitalista, no qual o trabalho excedente é convertido em lucro (Bottomore, 2012).
} 
A "força estranha" imposta pela divisão social do trabalho retirou do gênero humano o poder de refletir sobre a sua realidade por meio de um ângulo mais universal, sendo influenciado, preponderantemente, pelo prisma dos sujeitos detentores dos meios de produção. Este trabalho "estranhado", ao invés de realizar o sujeito que trabalha, faz com que este trabalhador se aliene no trabalho; assim, "[...] em lugar de reconhecer-se em suas próprias criações, o ser humano se sente ameaçado por elas; em lugar de libertar-se, acaba enrolado em novas opressões" (Konder, 2008, p. 30).

De acordo com Lukács (1978), o homem somente alcançará a liberdade a partir do momento que o trabalho for completamente dominado e interpretado pela humanidade, deixando para trás sua triste face coercitiva, a qual apresenta-se aos sujeitos como mero e único meio de assegurar a vida biológica. O trabalho deverá ser encarado como o primeiro carecimento da vida, como "manifestação da vida humana", conseguido através do livre emprego de si (idem, ibidem, 1978).

O alcance do equilíbrio entre o caráter natural e o caráter social do trabalho na práxis humana permite que o sujeito compreenda os esforços e sacrifícios que "[...] o presente custou ao passado e que o futuro custa ao presente [...]" bem como a "[...] concepção da atualidade como síntese do passado, de todas as gerações passadas, que se projeta no futuro [...]" (Gramsci, 2001, p. 43). Por meio de uma concepção histórico-ontológica do trabalho o homem cria os instrumentos necessários para uma melhor compreensão de sua práxis, de seu devir, permitindo expurgar todas as concepções mágicas e folclóricas que lhe foram impostas, e que lhe impedem perceber a realidade como uma totalidade (idem, 1982).

A práxis humana, diante desta perspectiva, encontra-se relacionada à ação "livre, universal, criativa e auto criativa" através da qual o gênero humano produz e transforma o seu mundo, sua história e a si próprio; uma atividade tão singular que o distancia profundamente dos demais animais (Bottomore, 2012).

Segundo Frigotto (2009), o princípio educativo do trabalho não é tratado por Marx como um recurso diretamente pedagógico, mas como um processo capaz de socializar e internalizar o preceito de que "[...] todo ser humano, tem o imperativo de, pelo trabalho, buscar meios de sua reprodução - primeiramente biológica, e na base desse imperativo da necessidade de criar e dilatar o mundo efetivamente livre" (idem, ibidem, p. 189).

Portanto, para que o trabalho se constitua de um princípio educativo, ele deve ser apresentado ao homem uma inteira "manifestação de si", ou seja, como um elemento que lhe confere o patamar de humano, de ser social. Para tanto, torna-se necessário que os indivíduos se apropriem da totalidade das forças produtivas bem como das faculdades mentais que essa força produtiva necessita, tornando o homem um indivíduo completo. Segundo Marx \& Engels (1998), a partir do momento que o homem se aproprie do modo de produção e das forças produtivas, 0 trabalho perde sua face "estranha", transformando-se em atividade livre, na qual o sujeito imprime o livre emprego de suas atividades mentais e materiais na produção de sua existência.

Isto posto, deve-se acentuar ao indivíduo o fato inexorável de que "o que o homem é, é-o pelo trabalho" (Saviani, 2007, p. 154), sendo o elemento que the confere o status de ser social. Ao se compreender as bases teóricas, técnicas, históricas e sociais que fundamentam a produção da existência humana moderna, o trabalho deixa de ser um elemento estiolador da vida humana, para tornar-se o veículo no qual o homem expressa a "manifestação de si". Esta, pois, é a 
concepção que fundamenta o princípio educativo do trabalho a partir do qual, e no qual, será possível apontar para a superação do sistema capitalista que aliena, explora e aprisiona o gênero humano.

\section{A FORMAÇÃO DO INTELECTUAL ORGÂNICO POR MEIO DA EDUCAÇÃO INTEGRADA}

Segundo Marx \& Engels (1998), a divisão do trabalho se consolida com a separação entre trabalho material e trabalho intelectual, permitindo à alguns indivíduos a emancipação do trabalho físico para se dedicarem ao gozo, ao desenvolvimento das faculdades mentais, à criação, à "teoria pura", etc., relegando ao restante da população a função trabalhar e de produzir a existência de todos.

Essa classe que detém dos meios de produção, detém, por consequência, a produção intelectual de toda a sociedade, submetendo e condicionando a massa privada de propriedade ao seu pensamento dominante. Isto posto, compreende-se que a classe dominante têm consciência de seu "poder de dominação", atuando, por meio de seus próprios intelectuais, como "produtores de ideias", fazendo com que as suas ideias sejam, portanto, as ideias dominantes de sua época histórica em toda a sua extensão (Marx \& Engels, 1998).

Numa perspectiva gramsciana, os intelectuais constituem, tradicionalmente, uma classe de indivíduos formada pela mesma camada que constitui a burguesia ${ }^{2}$. A relação existente entre os intelectuais e a produção industrial se dá de forma "mediatizada" pelo contexto social e pelo conjunto de "superestruturas" ${ }^{3}$ nas quais os intelectuais desempenham o papel de representantes do grupo social dominante. Estes indivíduos, exercem funções de dirigentes e especialistas, garantindo a hegemonia ${ }^{4}$ social e o governo político por meio da construção de um consenso espontâneo. Construído historicamente, este consenso encontra-se baseado no prestígio social do grupo dominante que induz, inculca e impõe sobre as massas a aceitação da função do intelectual (Gramsci, 1982).

Com a intensificação da atividade industrial, temos a conversão e apropriação da ciência como um meio de produção, esta passa a ser incorporada no processo produtivo bem como no âmbito social. Neste momento, para que fosse possível o desenvolvimento da indústria torna-se imprescindível que mais indivíduos dominem o mundo das linguagens e códigos, sendo necessário, então, a alfabetização e instrução das massas. Porém, a escola que nasce no seio da atividade industrial é uma escola que diferencia drasticamente o trabalho manual e o trabalho intelectual, por meio da qual se desqualifica o primeiro e qualifica o segundo. Surgem assim, as escolas de formação geral e as escolas técnicas ou profissionais, segregando seus alunos e, por consequência, a sociedade em dois grandes grupos:

\footnotetext{
${ }^{2} \mathrm{O}$ conceito de burguesia, é utilizado por Antônio Gramsci, dentro de uma perspectiva marxista, fazendo referência à classe que possui os meios de produção, dando a vida ao capitalismo (Liguori \& Voza, 2017).

${ }^{3}$ De forma resumida, pode-se afirmar que a superestrutura faz relação com as formas de Estado e a consciência social, ambos elementos fundamentados na estrutura econômica da sociedade, denominada por Marx de infraestrutura (Bottomore, 2012).

${ }^{4}$ Diante de uma perspectiva gramsciana, pode-se compreender hegemonia como uma expressão ampla que indica "sua particular valência em relação à genérica acepção de 'preeminência', 'supremacia', [...] construindo um espectro extremamente amplo de significados em um âmbito de contextos que vai da economia até a literatura, da religião até a antropologia, da psicologia até a linguística" (Liguori \& Voza, 22017, p. 365).
} 
[...] aquele das profissões manuais para as quais se requeria uma formação prática limitada à execução de tarefas mais ou menos delimitadas, dispensando-se o domínio dos respectivos fundamentos teóricos; e aquele das profissões intelectuais para as quais se requeria domínio teórico amplo a fim de preparar as elites e representantes da classe dirigente para atuar nos diferentes setores da sociedade (Saviani, 2007, p. 159).

De acordo com Gramsci (2001), a intensa incorporação das ciências na vida humana da sociedade moderna é um reflexo da maior complexificação das atividades práticas, um processo que induz a criação de variados tipos de escolas com o intuito de formar os seus próprios dirigentes e especialistas. Deste modo, paralelamente à escola clássica e humanista, cada atividade prática cria para si escolas de diferentes níveis "[...] para inteiros ramos profissionais ou para profissões já especializadas e indicadas mediante uma precisa especificação" (idem, ibidem, p. 33). Trata-se de uma tendência, onde cada atividade prática cria sua escola profissionalizante ao passo que cada atividade intelectual cria seus próprios círculos de cultura.

O intelectual orgânico, apresentado por Gramsci (1982, 2001), constitui-se de um tipo de intelectual nascido "no mesmo terreno" de sua classe social, ou seja, trata-se de um sujeito criado e desenvolvido dentro de sua classe de origem, exercendo a função de organizar ideologicamente e politicamente seu estrato social. O "novo" intelectual orgânico, que atuará na luta contra o alienante modo de produção vigente, deverá surgir no interior da classe trabalhadora. Esse indivíduo, a partir da concreta vivência da realidade contraditória e desumanizante, instruirá toda a massa de trabalhadores que vivem apenas do trabalho em prol de suas próprias e verdadeiras necessidades.

Este processo evidencia relações já anunciadas por Marx \& Engels (2008), no Manifesto do Partido Comunista, onde os autores alertam que são as relações de produção que determinam as relações sociais. Deste modo, a medida que o capital reconfigura seus instrumentos de produção, criando novas atividades práticas, as relações sociais e os processos formativos também são reconfigurados, visando atender esta nova demanda. Não há estabilidade neste sistema, cabendo ao trabalhador se adequar constantemente, sendo forçado "[...] a encarar com serenidade sua posição social e suas relações recíprocas" (idem, ibidem, p. 14). A escola, diante desta perspectiva, atua como instrumento que assegura a dicotomia existente entre empregador e empregado, sujeito dirigente e sujeito que executa, sujeito que pensa e sujeito que "faz".

Todavia, é impossível fazer a distinção entre os intelectuais e os não-intelectuais, visto que toda atividade de caráter "muscular-nervoso" requer uma elaboração intelectual criadora, não existindo, portando, a possibilidade de se separar o homo faber do homo sapiens, ou seja, o sujeito que executa do sujeito que pensa (Gramsci, 1982).

A superação desta dicotomia, escola geral versus escola profissional, se faz mediante uma luta contra-hegemônica pautada numa educação que integre e permita a apropriação dos conhecimentos historicamente produzidos pela humanidade, da cultura, da ciência e dos instrumentos e técnicas necessários à (re)produção da existência humana bem como da riqueza social. Ao contrário de uma escola dual, esta se constitui de uma escola única, ou unitária, permitindo a assimilação das bases científicas, tecnológicas e históricas que fundamentam a produção atual, bem como permitem aos estudantes a liberdade de realizarem suas escolhas profissionais (Ramos, 2009). 
A educação integrada encontra suas bases na proposição da escola unitária gramsciana, a qual deve fundamenta-se na capacidade de proporcionar à todos os alunos uma atmosfera de intelectualidade, garantindo que os jovens se habituem à disciplina coletiva e adquiram noções e aptidões que favoreçam o seu desenvolvimento intelectual. A escola unitária, trata-se, portando, "[...] de uma escola única inicial de cultura geral, humanista, formativa, que equilibre de modo justo o desenvolvimento da capacidade de trabalhar manualmente (tecnicamente, industrialmente) e o desenvolvimento das capacidades de trabalho intelectual" (Gramsci, 2001, p. 33).

Cabe à escola, ter o trabalho como princípio educativo, explicitando, dentro dos conteúdos por ela ensinados, a teoria que fundamenta a produção da existência humana moderna, bem como as relações de força existentes dentro do processo produtivo. Como resultado, teremos um sujeito que compreende o mundo do trabalho como um todo, na sua ciência e na sua técnica, tornando-se emancipado (Ramos, 2009).

De acordo com Gramsci (1982), a criação de uma nova forma de "intectualismo" depende do desenvolvimento crítico da dimensão intelectual existente em cada atividade de caráter muscular-nervoso, apontando para um horizonte onde este mesmo esforço muscular-nervoso, este trabalho manual, fundamente uma nova e integral concepção de mundo. Deste modo, a formação técnica, mesmo a mais primitiva e simplificada, deve ser atrelada ao desenvolvimento intelectual, permitindo alicerçar a base para a formação do "novo tipo de intelectual".

Para Marx \& Engels (1998), a verdadeira riqueza intelectual do indivíduo está atrelada a sua capacidade de perceber por um prisma mais geral a "riqueza das relações reais". A educação integrada deve partir desta compreensão, permitindo ao seu aluno se libertar das limitações ideológicas que lhe foram impostas, colocando-o diante das relações materiais, práticas e intelectuais que permeiam o mundo e estruturam a produção industrial moderna, viabilizando o desvelar das peculiaridades e estranhezas inerentes às relações sociais capitalistas.

Ao se fornecer uma educação que integre o trabalho intelectual ao trabalho manual para a classe trabalhadora, permite-se que o homem incorpore a dimensão científica, histórica e social à sua atividade técnica específica, descortinando a face estranhada do trabalho. Por estarem alicerçados nas bases da escola unitária gramsciana, os trabalhadores conseguirão produzir o seu próprio intelectual orgânico, um sujeito com função dirigente e especialista, que compreende e reflete sobre as bases históricas, sociais e teóricas que alicerçam o mundo do trabalho, retomando a consciência dos demais indivíduos, garantindo a defesa da ideologia e do interesse de sua classe de origem.

\section{OS INSTITUTOS FEDERAIS DE EDUCAÇÃO, CIÊNCIA E TECNOLOGIA COMO VEÍCULO DE "TRAVESSIA" PARA A ATIVIDADE AUTODETERMINADA}

Trazendo esta discussão sobre a formação dos indivíduos que compõem a classe trabalhadora para realidade brasileira, encontramos em Moura (2007) uma reflexão acerca dos moldes sob os quais se assentou a modalidade de Educação Profissional no Brasil, tornando evidente o seu histórico rebaixamento frente à educação propedêutica fornecida às elites. A Educação Profissional foi tradicionalmente relegada à segundo plano e destinada às classes menos favorecidas, apresentando um caráter muito mais assistencialista do que formativo. 
Institucionalizada em 1909 pela Escola de Aprendizes e Artífices, a formação profissional iniciou-se destinada aos "pobres e humildes", almejando torná-los meros executores de atividades manuais. Esta formação ocorria em separado da educação básica, voltando-se à capacitação técnica, visto que seu objetivo era atender tão simplesmente as necessidades emergentes da agricultura e da indústria (Moura, 2007).

Esta dicotomia entre Educação Profissional versus Educação Básica no Brasil foi majoritária durante toda a sua história da educação. Característica refletida, também, na Lei de Diretrizes e Bases da Educação Nacional (LDBEN) n. 9.394 de 1996, a qual, segundo Ramos (2009), retirou do currículo a categoria trabalho nas suas dimensões teóricas, técnicas e históricas em prol de uma formação genérica, sem nenhuma relação com o concreto. Este marco legal afasta da educação básica brasileira a possibilidade do indivíduo compreender o mundo do trabalho em sua totalidade.

De acordo com Moura (2007), nesta legislação a modalidade de Educação Profissional apresenta-se como um apêndice à Educação Básica, fator evidenciado dentro dos seus artigos 39 até o 42, nos quais a LDBEN trata especificadamente da Educação Profissional, transparecendo a concepção de complementaridade à Educação Básica.

O caráter dual da educação brasileira reflete uma contraditoriedade concernente ao modo de produção capitalista, o qual, segundo Antunes (2007), visa assegurar tão somente a autorreprodução de si próprio. Deste modo, não é favorável ao capital que a escola esclareça ao sujeito as contradições existentes dentro do modo de produção capitalista, sendo mais viável a não discussão das dimensões histórico-ontológicas do trabalho acompanhada de uma formação genérica, sem relação e reflexão com a realidade, assim como preconizada pela LDBEN n.으 9.394/96.

Este processo poder ser analisado através do prisma da ideologia dos grupos dominantes, que segundo Lukács (1978, p. 17) "[...] estiveram e estão a serviço da conservação e do desenvolvimento da adequação do gênero em si", ou seja, tratam-se de ideologias que estão à serviço da conformação do homem à realidade tal como apresentada à ele, inculcando a não necessidade de intervir ou questionar sobre ela.

Legalmente, o mecanismo encontrado para manter o trabalho apartado da Educação Básica se consolidou com o Decreto n. 2.208/97, que regulamenta o § 20 do art. 36 e os arts. 39 a 42 da Lei no 9.394/1996. Segundo Ramos (2009), este decreto, ao normatizar a Educação Profissional, proibiu a oferta da formação técnica integrada ${ }^{5}$ ao Ensino Médio. Uma posição que pode ser resumida ao seu Art. 5ㅇ, o qual faz a seguinte afirmação "A educação profissional de nível técnico terá organização curricular própria e independente do ensino médio, podendo ser oferecida de forma concomitante ou sequencial a este" (Brasil, 1997, grifo nosso). Torna-se evidente a imposição do não entrelaçamento entre o mundo do trabalho e o mundo escolar, permitindo apenas uma formação técnica com caráter complementar, a ser cursada em separado do Ensino Médio.

\footnotetext{
${ }^{5}$ A formação técnica pode ser ofertada mediante três formas: integrada, concomitante e subsequente. Na forma integrada, o aluno, mediante uma única matrícula, cursa o ensino técnico e o ensino médio, aproximando, em tese, a teoria da prática. No formato concomitante, o aluno cursa ao mesmo tempo curso técnico e o ensino médio, todavia são formações distintas, não tendo relação uma com a outra, apresentando, portanto, duas matrículas. Por fim, a formação técnica subsequente, ocorre posteriormente ao jovem ou adulto concluir o ensino médio, sendo também uma formação desvinculada da educação básica (Ramos, 2009).
} 
Frigotto, Ciavatta \& Ramos (2012) afirmam que o Decreto n.o 2.208/97 constituiu-se de um mecanismo que expressava um plano de ação neoconservador ou neoliberal, por meio do qual impelia uma regressão educacional e social e, principalmente, assegurava, mais uma vez, a dualidade educacional brasileira.

Este receio de trazer a Educação Profissional para dentro do Ensino Médio pode ser explicado dentro da perspectiva gramsciana. Segundo Gramsci (1982), a última fase de sua escola unitária - correspondente ao nosso atual Ensino Médio - é a etapa decisiva na formação do intelectual orgânico e, por consequência, na produção de trabalhadores que defendam a ideologia e o interesse de sua classe de origem. Assim, o Ensino Médio, por se constituir de um nível de ensino cujos alunos encontram-se na interface entre o sujeito aluno e o sujeito trabalhador, a não discussão da categoria trabalho nas suas facetas ontológicas, históricas e econômicas asseguram a não reflexão da classe trabalhadora garantindo, por consequência, hegemonia do grupo social dominante.

Um movimento de oposição à esta concepção inferiorizada da formação profissional, formalizou-se ano de 2004, através do Decreto n.o 5.154 que, ao revogar o Decreto 2.208/97, instituiu, por meio de mecanismos legais, a possibilidade de se integrar o Ensino Médio à Educação Profissional mediante matrícula única, configurando como uma possibilidade de trazer para dentro do espaço escolar a ciência, a técnica e a teoria que permeiam o mundo do trabalho. Todavia, segundo Moura (2007), com este decreto o Ensino Médio no Brasil ficou sem identidade, pois não houve investimento para sua real implementação em todas as escolas públicas estaduais, ao passo que as escolas privadas continuaram - e continuam - fornecendo um ensino puramente propedêutico orientado pela aprovação no vestibular.

O Decreto $n$. o 5.154/2004 assinala a busca pela consolidação da base unitária para ensino médio, adequando-se à especificidade da juventude brasileira, cuja formação para o trabalho é uma imposição da realidade. Trata-se de um instrumento que permite aos jovens e adultos alargarem os seus horizontes por meio da formação para o exercício de profissões técnicas. Deste modo, "[...] o ensino médio integrado sobre uma base unitária de formação geral, é uma condição necessária para se fazer a "travessia" para uma nova realidade" (Frigotto, Ciavatta \& Ramos, 2012, p. 43, grifo nosso).

O mecanismo encontrado expandir a oferta de Ensino Médio integrado à formação técnica se consolidou no ano de 2008 por meio da Lei n. 11.892, que institui a Rede Federal de Educação Profissional, Científica e Tecnológica, criando um "novo" modelo de Educação Profissional e Tecnológica no Brasil. Surgiram os denominados Institutos Federais de Educação, Ciência e Tecnologia pautados numa "[...] concepção de Educação Profissional e Tecnológica EPT focada na formação omnilateral da pessoa, unindo ensino, pesquisa e extensão. Essa concepção tem como centralidade o indivíduo e seu coletivo e não o mercado de trabalho" (Aguiar \& Pacheco, 2017, p. 13-14, grifo nosso).

Segundo Manacorda (2011), esta proposição de uma formação omnilateral aponta para "o pleno desenvolvimento humano", sendo alcançada por intermédio de três pilares: a formação intelectual, a educação física e o ensino politécnico. Este último, ensino politécnico, apresenta a função de transmitir os fundamentos científicos gerais inerentes aos processos produtivos e ao mesmo tempo permitir que o aluno saiba manusear os instrumentos necessários ao desempenho todas as profissões. Para tanto, todos os indivíduos devem, juntos, pensar e atuar, 
“E para tal fim, precisa de uma educação que incorpore instrução tecnológica, teórica e prática, finalmente total, do homem realmente completo, não mais, platonicamente voltada só para completar a formação cultural, mas, para todas as formas da atividade humana, visando o homem onilateral." (Manacorda, 2012, p. 11).

Saviani (2007), afirma que uma educação omnilateral, alicerçada no ensino politécnico, permite que sujeito extrapole a atividade específica que lhe foi imposta pela divisão do trabalho regido sob o modo de produção capitalista. Ao se permitir o pleno desenvolvimento do homem, assim como pressupõem os Institutos Federais de Educação, Ciência e Tecnologia, aponta-se para um novo patamar social no qual a divisão do trabalho se dá de forma "[...] voluntária e consciente, envolvendo uma variedade indefinida de ocupações produtivas em que ciência e trabalho coincidem" (idem, ibidem, p. 164).

Os Institutos Federais de Educação, Ciência e Tecnologia, assim como as demais escolas que compõem a Rede Federal de Educação Profissional e Tecnológica, ao ofertarem um Ensino Médio integrado à Educação Profissional se constituem de uma grande "possibilidade para os filhos da classe trabalhadora [...]" (Moura, 2007, p. 21). Por se assentarem sob os pilares da formação omnilateral, permitem o desenvolvimento das capacidades humanas bem como a compreensão crítica da realidade e do mundo do trabalho, podendo potencialmente "[...] contribuir para uma efetiva (re)construção de uma identidade própria para o ensino médio brasileiro" (idem, ibidem, p. 21).

De acordo com Aguiar \& Pacheco (2017), os Institutos Federais não se configuram nem como a "velha escola técnica" nem como "universidades", trazendo um novo conceito de Educação Profissional e Tecnológica atuando como verdadeiros veículos de promoção de uma educação integrada pautada na aproximação dos estudos teóricos, políticos e tecnológicos, visando perceber as relações socioeconômicas presentes no mundo e, a partir daí, transformá-lo.

Esta perspectiva formativa permite ao aluno desvendar o lado "estranhado" do trabalho e transformá-lo em um instrumento capaz de responder as suas necessidades. Segundo Antunes (2007), partir da compreensão do caráter ontológico inerente ao trabalho, este passa a ser enxergado como uma dimensão da realização humana, na qual o homem expressa a sua omnilateralidade, alicerçando uma "[...] atividade vital cheia de sentido, autodeterminada, para além da divisão hierárquica que subordina o trabalho ao capita [...]l” (idem, ibidem, p. 177).

De acordo com Lukács (1978), a atividade autodeterminada não é uma possibilidade dada de forma espontânea ou mágica aos homens. Existe uma inteira e estreita relação entre o reino da liberdade com o reino da necessidade, visto que o homem só consegue ser livre após satisfazer suas necessidades de ordem econômico-social, ou seja, somente após garantir a sua (re)produção. Isto posto, compreende-se que

A liberdade, bem como uma possibilidade, não é algo dado por natureza, não é um dom do "alto" e nem sequer uma parte integrante - de origem misteriosa - do ser humano. É o produto da própria atividade humana, que decerto sempre atinge concretamente alguma coisa diferente daquilo que se propusera, mas que suas consequências dilata objetivamente e de modo contínuo - o espaço no qual a liberdade se torna possível; e tal dilatação ocorre, precisamente, de modo direto, no processo de desenvolvimento econômico, no qual, por um lado, acresce-se o número, o alcance etc., das decisões humanas entre alternativas, e, por outro, eleva-se ao mesmo tempo a capacidade dos homens, na medida em que se elevam as tarefas a eles colocadas por sua própria atividade. (Lukács, 1978, p. 15).

Esta formação para o trabalho, portanto, não pretende adequar o gênero "em-si", mas ao contrário, objetiva evidenciar aos seus estudantes que para se alcançar a liberdade, o tempo livre e a atividade autodeterminada é necessário, primeiramente compreender as bases que fundamentam a produção moderna e por meio dela atuar, trabalhar e satisfazer as necessidades 
humanas. Assim, o sujeito compreende que para que todos tenham acesso ao "reino da liberdade" é necessário também que todos os indivíduos participem dos processos de produção da existência humana, ou seja, compreende que "o homem deve adquirir sua própria liberdade através de sua própria atuação" (Lukács, 1978, p. 16).

Com base nas acepções expostas neste texto, pode-se depreender que os Institutos Federais de Educação, Ciência e Tecnologia ao ofertarem a formação técnica integrada ao Ensino Médio pode garantir o intercâmbio do conhecimento historicamente produzido com o mundo do trabalho, desempenhando, assim, uma dupla função: permitem que seus alunos compreendam as bases científicas e tecnológicas que fundamentam a produção moderna ao mesmo tempo em que desvelam as relações de poder que asseguram o modo de produção capitalista. Isto posto, compreende-se a função de tais instituições na formação dos intelectuais orgânicos da classe trabalhadora, os quais atuarão como dirigentes e especialistas na luta contrahegemônica.

\section{5 À GUISA DE CONCLUSÃO}

Segundo Marx \& Engels (1998, p. 3), "[...] os homens sempre tiveram ideias falsas a respeito de si mesmos, daquilo que são ou deveriam ser", um reflexo da nebulosa realidade que lhes é apresentada. Este processo alienador se faz mediante o modo de produção capitalista que torna a atividade desempenhada pelos trabalhadores uma força "estranha", atuando de forma coercitiva, impedindo-os de compreenderem o processo produtivo como um todo bem como as relações sociais que sustentam a (re)produção da existência humana.

Os trabalhadores tornam-se sujeitos explorados tanto no trabalho produtivo (ou seja, aquela atividade que produz diretamente mais-valia) quanto no trabalho improdutivo, um processo que assegura a não consciência de classe parte da massa de trabalhadores fazendo com que tome os vocábulos trabalho e emprego como sinônimos (Frigotto, 2009).

A escola, dentro deste sistema, apresenta-se tradicionalmente dividida: de um lado, as escolas básicas de formação propedêutica e, de outro, das escolas profissionalizantes que, tão somente, asseguram a formação técnica. Segundo Saviani (2007), trata-se de duas escolas para dois tipos de alunos cujos papéis sociais encontram-se claramente definidos, temos assim o desenvolvimento das potencialidades intelectuais para a classe dominante, em detrimento de uma formação instrumental para a classe trabalhadora.

É notório ressaltar que ao longo da história da educação brasileira a etapa correspondente ao nosso atual Ensino Médio se constituiu de um nível da educação básica permeado por disputas sob o seu ideal formativo (Moura, 2007). Justifica-se esta "preocupação", pois este momento é, para a grande maioria da população brasileira, a interface que separa o aluno do futuro trabalhador. Deste modo, a escola pode se configurar como um instrumento para conformação do sujeito "em-si" ou para fazê-lo refletir sobre a sua realidade.

A perspectiva de formação omnilateral aponta para uma perspectiva ampla de formação humana, o qual permite a compreensão da realidade como um todo. Trata-se de um ensino que aponta para um horizonte educativo em que exista a unicidade entre o trabalho manual e intelectual, uma proposição muito diferente do ensino pluriprofissional, que objetiva tão somente ter um trabalhador adaptável e "subordinável" as várias profissões (Manacorda, 2011).

Gramsci (2001), ao propor sua escola unitária, fundamenta-se nestas proposições, visando desenvolver no indivíduo todas as suas potencialidades, tanto as de caráter muscular-nervoso, quanto as de caráter intelectual. Segundo o autor, "a escola é o instrumento para elaborar os intelectuais de diversos níveis" (idem, ibidem, p, 18), cabendo à esta instituição, desenvolver as 
bases humanistas nos sujeitos que compõem a classe trabalhadora, fazendo emergir de dentro da própria classe os "novos" - e próprios -intelectuais orgânicos.

Partindo do pressuposto que a formação para o trabalho ofertada pelos Institutos Federais de Educação, Ciência e Tecnologia pauta-se em um projeto de ensino que aponta para o caráter omnilateral de formação humana (Aguiar \& Pacheco, 2017) e encontra-se alicerçada em um currículo integrado construído à luz da escola unitária gramsciana, podemos afirmar que os seus alunos podem vislumbrar uma realidade para além de sua face "estranha", percebendo que a "[...] divisão dos homens entre destinados ao trabalho e outros à ciência, uns à produção e outros ao consumo, uns ao cansaço ou outros ao gozo, é o nó das contradições da sociedade capitalista [...]" (Manacorda, 2011, p. 11). Em suma, tais instituições formam sujeitos que compreendem que é direito e dever de todos "pensar e atuar".

Tais instituições ao buscarem desvelar as relações de força existentes dentro do atual modo de produção da existência humana, permitem que os sujeitos compreendam que a exploração do homem pelo homem não é algo natural. O trabalho, neste momento, abandona sua face "enclausuradora", apresentando-se como instrumento por meio do qual os homens se constituem "humanos", permitindo "[...] criar as condições materiais necessárias e um campo de possibilidades para o livre emprego de si" (Lukács, 1978, p. 16).

A formação técnica integrada à educação básica objetiva formar o homem em sua completude, um produto que requer uma perspectiva educativa na qual se integre teoria, prática e instrução tecnológica, permitindo "[...] desenvolvimento completo de uma personalidade capaz de operar com o pensamento e com as mãos, ou seja, de associar a cultura e o trabalho" (Manacorda, 2011, p. 12).

Destarte, podemos afirmar que a formação para o trabalho dos Institutos Federais de Educação, Ciência e Tecnologia, ao se alicerçarem sob os ideais da formação omnilateral, permitem aos seus alunos, serem, não apenas técnicos, mas sim dirigentes das atividades que executam dentro do mundo da produção. Estes sujeitos, por compreenderem a dimensão ontológica do trabalho, têm a possibilidade e, principalmente, a potencialidade de romper com a face "estranha" do trabalho, compreendendo-o como uma atividade realizadora. Assim, o trabalho deixa de ser a alienante "certidão pra nascer e a concessão pra sorrir", cantada por Chico Buarque, tornando-se, ontologicamente, o veículo que faz o homem (re)nascer e sorrir.

\section{REFERÊNCIAS}

Aguiar, L. E. V. \& Pacheco, E. M. (2017). Os Institutos Federais de Educação Ciência e Tecnologia como política pública. In: M. B. Anjos \& G. Rôsas, G (Orgs), As políticas públicas e o papel social dos Institutos Federais de Educação, Ciência e Tecnologia (pp. 13-35). Natal, RN: IFRN.

Antunes, R. (2007). Os sentidos do trabalho: Ensaio sobre a afirmação e a negociação do trabalho. São Paulo, SP: Boitempo Editorial.

Brasil (1996). Lei n.o 9.394, de 20 de dezembro de 1996. Estabelece as diretrizes e bases da educação nacional. Brasília, DF. Disponível em: < http://www.planalto.gov.br/ccivil_03/_ato2007-2010/2008/lei/l11892.htm>. Acesso 08 jan. 2018.

Brasil. (1997). Decreto n.o 2.208, de 17 de abril de 1997. Regulamenta o § 20 do art. 36 e os arts. 39 a 42 da Lei no 9.394, de 20 de dezembro de 1996, que estabelece as diretrizes e bases da educação nacional. Brasília, DF. Disponível em: <http://www.planalto.gov.br/ccivil_03/decreto/d2208.htm >. Acesso em 08 jan. 2018. 
Brasil. (2004). Decreto n.o 5.154, de 23 de julho de 2004. Regulamenta o § 20 do art. 36 e os arts. 39 a 41 da Lei no 9.394, de 20 de dezembro de 1996, que estabelece as diretrizes e bases da educação nacional, e dá outras providências. Brasília, DF. Disponível em: < http://www.planalto.gov.br/ccivil_03/_ato2004-2006/2004/decreto/d5154.htm>. Acesso 30 dez. 2017.

Brasil. (2008). Lei n.o 11.892, de 29 de dezembro de 2008. Institui a Rede Federal de Educação Profissional, Científica e Tecnológica, cria os Institutos Federais de Educação, Ciência e Tecnologia, e dá outras providências. Brasília, DF. Disponível em: < http://www.planalto.gov.br/ccivil_03/_ato2007-2010/2008/lei/l11892.htm>. Acesso 30 dez. 2017

Bottomore, T. (2012). Dicionário do pensamento marxista (2.ed). Rio de Janeiro, RJ: Zahar.

Engels, F. (2006). O Papel do Trabalho na Transformação do Macaco em Homem. Publicado pela primeira vez em 1896 em Neue Zelt. Trabalho Necessário, 4(4), pp. 1-9. Disponível em <http://www.uff.br/trabalhonecessario/images/TN04\%20ENGELS,\%20F.pdf >. Acesso 9 jan. 2018.

Frigotto, G. (2009). A polissemia da categoria trabalho e a batalha das ideias nas sociedades de classe. Revista brasileira de Educação, 14(40), jan/abri, pp. 168-194. Disponível em <http://www.scielo.br/pdf/rbedu/v14n40/v14n40a14.pdf>. Acesso 29 set. 2017.

Frigotto, G., Ciavatta, M. \& Ramos, M. (2012). A gênese do Decreto n. 5.154/2004: um debate no contexto controverso da democracia restrita. In: M. Ramos, G. Frigotto \& M. Ciavatta (Orgs). Ensino Médio Integrado: Concepção e Contradições (3.ed. pp. 21-56). São Paulo, SP: Cortez.

Gramsci, A. (1982). Os Intelectuais e a Organização da Cultura. Rio de Janeiro, RJ: Editora Civilização Brasileira, 1982.

Gramsci, A. (2001). Cadernos do cárcere, volume 2 (2.ed). Rio de Janeiro, RJ: Editora Civilização Brasileira.

Konder, L. (2008). O que é dialética (28.ed.). São Paulo, SP: Brasiliense.

Hollanda, C. B. (1971). Construção. In: Homônimo (Disco Vinil, faixa 4). Rio de Janeiro, SP: Phonogram/Philips.

Liguori, G. \& Voza, P. (2017). Dicionário Gramsciano (1.ed.). São Paulo, SP: Boitempo.

Lukács, G. (1978). As bases ontológicas do pensamento e da atividade do homem. Temas de Ciências Humanas, 4, pp. 1-18. São Paulo, SP: Livraria Editora Ciências Humanas.

Manacorda, M. A. (2011). Marx e a formação do homem. Revista HISTEDBR On-line, número especial, abr, pp. 6-15. Disponível em: <https://periodicos.sbu.unicamp.br/ojs/index.php/histedbr/article/view/8639891/7454> . Acesso 11 jan. 2018.

Marx, K. \& Engels, F. (1998). A ideologia alemã. São Paulo, SP: Editora Martins Fontes.

Marx, K. \& Engels, F. (2008). Manifesto do partido comunista (1.ed.). São Paulo, SP: Expressão Popular.

Moura, D. H. (2007). Educação Básica e Educação Profissional e Tecnológica: dualidade histórica e perspectivas e integração. Holos, 23(2), pp. 4-30. Disponível em: <http://www2.ifrn.edu.br/ojs/index.php/HOLOS/article/view/11/110>. Acesso 23 mar. 2017. 
Ramos, M. N. (2009). Concepção do ensino médio integrado. In: R. Araújo \& E. Teodoro (Orgs). Ensino Médio Integrado no Pará como Política Pública (pp. 144-182). Belém, PA: SEDUC-PA.

Saviani, D. (2007). Trabalho e educação: fundamentos ontológicos e históricos. Revista Brasileira de Educação, 34(12), jan/abr pp. 152-180. Disponível em: <http://www.scielo.br/pdf/rbedu/v12n34/a12v1234.pdf>. Acesso 20 mar. 2017. 